\title{
Salivary glands of fetuses are adversely affected by artificial food colorings in rats

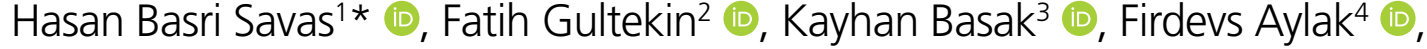 Duygu Kumbul Doguc ${ }^{4} \odot$, Osman Gurdal ${ }^{5}$
}

\section{SUMMARY}

OBJECTIVE: Artificial food colorings, as types of food additives, are widely used at present in daily life. We aimed to investigate the effects of exposure to artificial food colorings during the intrauterine period on the salivary glands in adulthood.

METHODS: A total of 30 Wistar albino female pregnant rats were included in this study. The treatment group was given a mixture of nine artificial food colorings at no observed adverse-effect-level doses. Neither mothers nor offspring were fed with food colorings after delivery. When the offspring became adults, they were sacrificed, and the possible histopathological and immunohistochemical effects of artificial food colorings on the salivary glands were investigated. In these glands, anti-matrix metallopeptidase 2 (anti-MMP2), anti-MMP9, anti-tissue inhibitor of metalloproteinases (TIMP) metallopeptidase inhibitor 1 (anti-TIMP1), anti-TIMP2, and anti-TIMP3 were examined. RESULTS: The expressions of anti-MMP2, anti-TIMP1, anti-TIMP2, and anti-TIMP3 parameters were found to be higher in treatment groups $(p<0.05)$.

CONCLUSION: It was suggested that intrauterine exposure of synthetic food colorings may lead to deterioration of the tissue structure of the salivary glands in adulthood, thereby increasing susceptibility to chronic illnesses including malignancy and chronic inflammation. Therefore, pregnant women should give importance to their nutrition in terms of foods containing synthetic colorings.

KEYWORDS: Food coloring agents. Saliva. Rats. Toxicity. Inflammation.

\section{INTRODUCTION}

Food additives are used to fix, maintain, and improve biological and nutritional values during the processing, preparation, manufacturing, packaging, and storage stages of foods. These additives are also defined as mixtures of substances or substances of natural or artificial origin that are purposefully used to prevent undesirable changes that may occur in the food and improve the quality and shelf life of the product ${ }^{1,2}$.

Most of the food additives like drugs are substances that can be metabolized by the body, and toxic effects may occur when they are used at higher doses than the approved ones ${ }^{3}$. A toxicological test is carried out mainly on experimental animals to determine the safety of a chemical compound that is present in foodstuffs for any reason and that is determined to be present in the final product. The overall objective of toxicological tests on experimental animals is to determine the no-observed-adverse-effect level (NOAEL) value ${ }^{1,2}$. Then, the acceptable daily intake (ADI) levels are determined based on the NOAEL values ${ }^{4,5}$.

Chronic and neuropsychological illnesses, such as cancer, diabetes, hypertension, autism, and hyperactivity, are influenced

\footnotetext{
${ }^{1}$ Alanya Alaaddin Keykubat University, Faculty of Medicine, Department of Medical Biochemistry, Alanya/Antalya, Turkey.

${ }^{2}$ University of Health Sciences, International Faculty of Medicine, Department of Medical Biochemistry, Istanbul, Turkey.

${ }^{3}$ Kartal Lütfi Kırdar Training and Research Hospital, Pathology Department, Istanbul, Turkey.

${ }^{4}$ Suleyman Demirel University, Medical Faculty, Medical Biochemistry Department, Isparta, Turkey.

${ }^{5}$ Suleyman Demirel University, Medical Faculty, Department of Biostatistics and Medical Informatics, Isparta, Turkey.

*Corresponding author: hasan.savas@alanya.edu.tr

Conflicts of interest: the authors declare there are no conflicts of interest. Funding: this study was supported by the Scientific and Technological Research Council of Turkey with project number $215 \$ 116$.
}

Received on September 05, 2020. Accepted on September 18, 2020. 
by the genetic and environmental factors. One of the environmental factors worsening these illnesses may be food additives. Synthetic food colorings are used in many foods ${ }^{1,2}$.

Due to the widespread use of colorings, high exposure is inevitable. Parallel to the rapid climb of the number of consumers and unconscious consumption of higher quantities than recommended, several adverse effects may occur ${ }^{6-9}$.

This study aimed to find a possible link between the maternal exposure to synthetic food colorings and the structural deterioration of the salivary glands in adulthood.

\section{METHODS}

\section{Animal experiments}

All materials and tests carried out in this study were approved by the SDU Animal Experiments Local Ethics Committee (dated April 2, 2015, Decision $n^{\circ}: 08$ ) and used in accordance with the rules of the ethics committee. In this study, a total of 30 samples were initially used to provide genetic diversity from female Wistar albino rats.

Throughout the experiment, the rats were fed with water and feed (Standard Rat Fodder), and they were kept alive under standard light $(12 \mathrm{~h}$ light $/ 12 \mathrm{~h} \mathrm{dark})$ and heat $\left(23^{\circ} \mathrm{C}\right)$ conditions. The rats were randomly divided into two groups of 15 each, namely, the "control" and "food coloring" (treatment) groups. For the groups, drinking water was given from 1 week before the experimental animals became pregnant and continued until birth.

At the end of the first week, male rats were left for 7 days to provide mating in each cage. Food coloring and control group rats were conceived this way. The day the male rats were placed in the cages was accepted as the first day of the pregnancy of the female rats. Thirteen rats from the food coloring group and 12 rats from the control group gave birth. After the birth, the pups were kept with the mother for 1 month during the breastfeeding period, and then 48 rats were taken from the food coloring and control group rats. The results were as follows: control female $(n=12)$, treatment female $(\mathrm{n}=12)$, control male $(\mathrm{n}=12)$, and treatment male $(\mathrm{n}=12)$, each group consisting of 12 rats. When the rats were 3 months old, they were sacrificed under anesthesia, and their salivary glands were removed for pathological examination.

\section{Synthetic food colors}

Based on the NOAEL values, the maximum dose that each rat could receive per day was calculated. The NOAEL values are 100 times the $\mathrm{ADI}$ values ${ }^{1,2}$. The content of the coloring mixture that was used and the NOAEL values were as follows: erythrosine 10 $\mathrm{mg} / \mathrm{kg} /$ day, ponso $4 \mathrm{R} 70 \mathrm{mg} / \mathrm{kg} /$ day, allura red AC $700 \mathrm{mg} / \mathrm{kg} /$ day, sunset yellow FCF $250 \mathrm{mg} / \mathrm{kg} /$ day, tartrazine $750 \mathrm{mg} / \mathrm{kg} /$ day, amarant $15 \mathrm{mg} / \mathrm{kg} /$ day, brilliant blue FCF $600 \mathrm{mg} / \mathrm{kg} /$ day, azorubine and carmoisine $400 \mathrm{mg} / \mathrm{kg} / \mathrm{day}$, and indigotin $500 \mathrm{mg} /$ $\mathrm{kg} / \mathrm{day}^{1,2}$. The coloring mixture was given by oral gavage once daily in the order of $1 \mathrm{~mL} / 100 \mathrm{~g}$ weight of rats.

\section{Histopathological and immunohistochemical studies}

An immunohistochemical analysis was performed with a Ventana BenchMark ULTRA automatic coloring device using the Ventana ultraView universal DAB detection kit. All antibodies (Abcam, Cambridge, MA, USA) were scored semiquantitatively as follows: score 0 : no coloring, score 1: focal-weak coloring, and score 2: extensive coloring.

\section{Statistical analysis}

The statistical analysis was carried out using Mann-Whitney $U$-test for two independent ordinal data and Kruskal-Wallis $H$ test for more than two groups ${ }^{10,11}$. Statistical significance was defined as $\mathrm{p}<0.05$.

\section{RESULTS}

In this study, the results of the immunohistochemical analyses regarding the effects of food colorings on the salivary gland structure are shown in Table 1.

In these glands, anti-matrix metallopeptidase 2 (anti-MMP2), anti-MMP9, anti-tissue inhibitor of metalloproteinases (TIMP) metallopeptidase inhibitor 1 (anti-TIMP1), anti-TIMP2, and antiTIMP3 were examined. The expressions of all parameters, except anti-MMP9, were found to be higher in treatment groups $(\mathrm{p}<0.05)$.

\section{Immunohistochemistry imaging}

In our study, anti-MMP2, anti-TIMP1, anti-TIMP2, and antiTIMP3 expressions were found to be high. Images for the significant results are shown in Figure 1. Accordingly, the control and treatment groups were statistically significantly different in terms of immunohistochemistry imaging scores in MMP2 parotid duct (Figure 1.1 and 1.2), TIMP1 parotid stroma (Figure 1.3 and 1.4), TIMP1 submandibular (Figure 1.5 and 1.6), TIMP2 sublingual duct (Figure 1.7 and 1.8), TIMP2 submandibular serous (Figure 1.9 and 1.10), TIMP3 parotid serous (Figure 1.11 and 1.12), and TIMP3 submandibular stroma (Figure 1.13 and 1.14).

\section{DISCUSSION}

All food additives are considered safe when the codec is properly consumed. Considering the results of such studies, the use of some additives is terminated, while the safe limits of some additives are reduced. For example, Red2G, a colorant, has been identified as 
aniline, a carcinogenic substance, and prohibited in our bodies ${ }^{1,2}$. European Food Safety Authority has extensively investigated concerns about synthetic food colors, and investigations have been conducted on ADI (E123), brown HT (E155), sunset yellow FCF (E110), quinoline yellow (E104), and Ponso (ponceau) 4R $\mathrm{R}^{1,2}$.

Synthetic food colorings may have negative effects on the cellular level. For example, mitochondrial respiration may be suppressed by 16-100\%. However, it is not known how these effects are reflected in the clinic $^{12}$. In some studies, relationships between salivary gland pathologies and nutrition and the application of certain chemicals have been identified ${ }^{13-15}$. For example, administration of chronic isoproterenol leads to hypertrophy and hyperplasia in the salivary glands $s^{13}$. In the atrophic parotid glands that are induced by the liquid diet, asper cell apoptosis increases, while proliferative activity decreases ${ }^{14}$. Deferoxamine was shown to be effective in correcting the damage caused by radiation in the salivary glands ${ }^{15}$. It is important to reveal the negative effects of synthetic colors to which people are continuously being exposed at this point.

The aim of this study was to investigate the effects of nine food colors on many tissues. The tissues were analyzed, and this

Table 1. The p-values of immunohistochemical analyses determined using Kruskal-Wallis $H$ tests at $\alpha$ value of 0.05 .

\begin{tabular}{|c|c|c|c|c|}
\hline Name of the group & Name & Comparison & Mean rank & $p$ \\
\hline \multirow{2}{*}{ Anti-MMP2 } & \multirow{2}{*}{ Parotid gland duct } & Control male & 7.50 & \multirow{2}{*}{0.044} \\
\hline & & Treatment female & 13.50 & \\
\hline \multirow{16}{*}{ Anti-TIMP1 } & \multirow{2}{*}{ Parotid gland stroma } & Control male & 11.06 & \multirow{2}{*}{$<0.001$} \\
\hline & & Treatment male & 27.50 & \\
\hline & \multirow{4}{*}{ Submandibular gland serous gland } & Control male & 11.61 & \multirow{2}{*}{$<0.001$} \\
\hline & & Treatment male & 28.50 & \\
\hline & & Control female & 15.20 & \multirow{2}{*}{0.016} \\
\hline & & Treatment male & 22.80 & \\
\hline & \multirow{4}{*}{ Submandibular gland mucous gland } & Control female & 9.50 & \multirow{2}{*}{$<0.001$} \\
\hline & & Treatment male & 27.50 & \\
\hline & & Control female & 9.50 & \multirow{2}{*}{$<0.001$} \\
\hline & & Treatment female & 27.50 & \\
\hline & \multirow{6}{*}{ Submandibular gland stroma gland } & Control Male & 12.50 & \multirow{2}{*}{0.048} \\
\hline & & Treatment female & 24.50 & \\
\hline & & Control male & 12.50 & \multirow{2}{*}{0.002} \\
\hline & & Treatment male & 28.50 & \\
\hline & & Control female & 16.50 & \\
\hline & & Treatment male & 28.50 & 0.048 \\
\hline \multirow{4}{*}{ Anti-TIMP2 } & \multirow{2}{*}{ Submandibular gland serous gland } & Control female & 12.70 & \multirow{2}{*}{0.039} \\
\hline & & Treatment male & 24.86 & \\
\hline & \multirow{2}{*}{ Sublingual gland duct } & Control female & 11.11 & \multirow{2}{*}{0.033} \\
\hline & & Treatment female & 21.58 & \\
\hline \multirow{6}{*}{ Anti-TIMP3 } & \multirow{4}{*}{ Parotid gland serous gland } & Control female & 12.50 & \multirow{2}{*}{0.048} \\
\hline & & Control male & 24.50 & \\
\hline & & Control female & 12.50 & \multirow{2}{*}{0.012} \\
\hline & & Treatment male & 26.50 & \\
\hline & \multirow{2}{*}{ Submandibular gland stroma } & Control female & 15.30 & \multirow{2}{*}{0.035} \\
\hline & & Treatment male & 27.00 & \\
\hline
\end{tabular}

MMP2: matrix metallopeptidase 2; TIMP: tissue inhibitor of metalloproteinases; TIMP1: TIMP metallopeptidase inhibitor 1; TIMP2: TIMP metallopeptidase inhibitor 2; TIMP3: TIMP metallopeptidase inhibitor 3. 
study was published progressively as a financial support was found. Maternal exposure to artificial food colors and additives (AFCAs) apparently affects the expression of cytochrome P450 family 1 subfamily A polypeptide 1 (CYP1A1), glutathione-S-transferase (GST), and vascular endothelial growth factor (VEGF) in the skin². When the laryngeal tissue was investigated, significant decreases in goblet cell count and cilia loss were observed with AFCAs in maternally exposed rats $(p<0.05)$. The other study demonstrated that maternal exposure of AFCAs plays a role in the mucosal defense system and possibly in carcinogenesis ${ }^{1}$. In this part of the study, the salivary tissues were investigated.

In this study, anti-MMP2, anti-MMP9, anti-TIMP1, antiTIMP2, and anti-TIMP3 were examined. These parameters
1.1

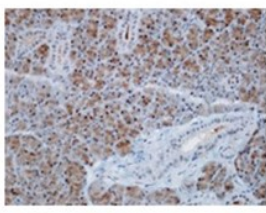

1.3

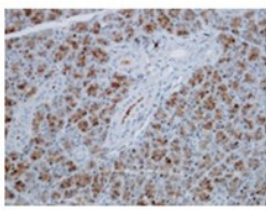

1.5

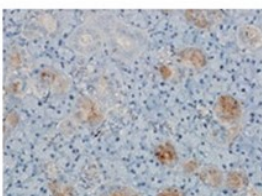

1.7

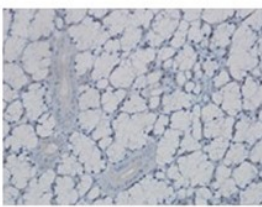

1.9

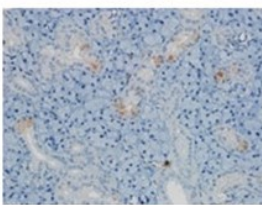

1.11

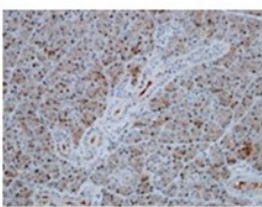

1.13

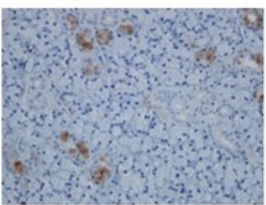

1.2

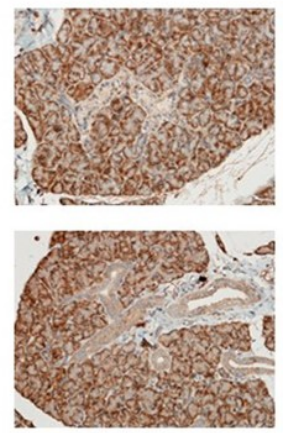

1.6

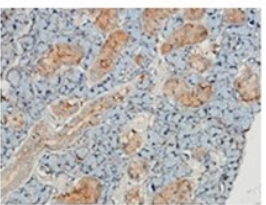

1.8

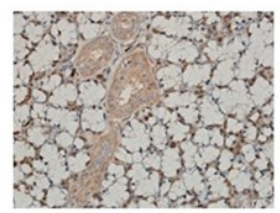

1.10

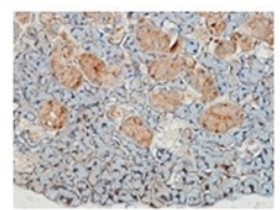

1.12

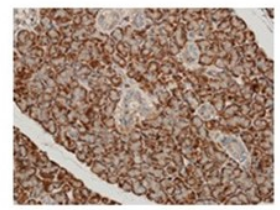

1.14

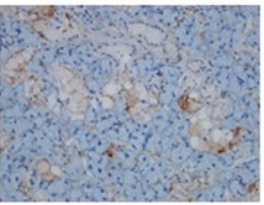

Figure 1. Immunohistochemical imaging. provide information about salivary gland morphogenesis. MMP9 and MMP2 are homologous enzymes containing the extracellular matrix and zinc in the active site, which can break down the basement membrane components ${ }^{16}$. MMPs are thought to play a role in the inflammatory cascade ${ }^{17}$. Tissue inhibitors of metalloproteinases (i.e., TIMP1, TIMP2, and TIMP3) are thought to inhibit the action of collagen-reducing enzymes and play an important role in the accumulation of increased extracellular matrix underlying fibrosis $^{18}$. In our study, anti-MMP2, anti-TIMP1, anti-TIMP2, and anti-TIMP3 expressions were found to be high. These results suggest that the intrauterine exposure to synthetic food colorings may lead to deterioration of the tissue structure of the salivary glands in adulthood, thereby increasing the susceptibility to chronic illnesses including malignancy and chronic inflammation.

The effects of synthetic food colorings, which are types of food additives, may be due to their own effects, or they may be caused by the synergistic effect resulting from the interaction with other substances in the organs ${ }^{12}$. As a matter of fact, it is known that some additives have a synergistic effect. For example, in a study conducted on mice and the synergistic effects of synthetic food colorings on nerve development, both tartrate and Brilliant Blue FCF showed no adverse effects when administered alone but suppressed nerve growth in the central nervous system when given in combination and at high doses ${ }^{19}$. In another in vitro nerve cell study, Brilliant Blue FCF, made by using quinolone yellow aspartame, increased the harmful effects of L-glutamic acid ${ }^{20}$.

In a study that investigated the synergistic effects of food colorants in rat liver cell cultures, it was shown that additives may increase the harmful effects of these carcinogens if they are exposed to a carcinogenic agent $\mathrm{t}^{21,22}$.

Consequently, anti-MMP2, anti-TIMP1, anti-TIMP2, and anti-TIMP3 expressions were found to be higher in treatment groups in our study. These results suggest that the intrauterine exposure to synthetic food colors may lead to deterioration of the tissue structure of the salivary glands in adulthood, thereby increasing the susceptibility to chronic illnesses including malignancy and chronic inflammation.

\section{AUTHORS' CONTRIBUTIONS}

All authors contributed equally for conceptualization, data curation, formal analysis, funding acquisition, investigation, methodology, project administration, supervision, and writing the original draft, review, and editing.

\section{DISCLOSURE}

Preliminary data of this study was presented in summary at the International Congress of Molecular Medicine in 2017. 


\section{REFERENCES}

1. Başak K, Doguç DK, Aylak F, Karadayi N, Gültekin F. Effects of maternally exposed food coloring additives on laryngeal histology in rats. J Environ Pathol Toxicol Oncol. 2014;33(2):123-30. https:// doi.org/10.1615/JEnvironPatholToxicolOncol.2014008723

2. Başak K, Başak PY, Doğuç DK, Aylak F, Oğuztüzün S, Bozer BM, et al. Does maternal exposure to artificial food coloring additives increase oxidative stress in the skin of rats? Hum Exp Toxicol. 2017;36(10):1023-30. https://doi. org/10.1177/0960327116678297

3. Winkler HC, Notter T, Meyer U, Naegeli H. Critical review of the safety assessment of titanium dioxide additives in food. J Nanobiotechnology. 2018;16(1):51. https://doi.org/10.1186/ s12951-018-0376-8

4. Wüthrich B. Adverse reactions to food additives. Ann Allergy. 1993;71(4):379-84. PMID: 8214803

5. Mantovani A, Maranghi F, Purificato I, Macrì A. Assessment of feed additives and contaminants: an essential component of food safety. Ann Ist Super Sanita. 2006;42(4):427-32. PMID: 17361066

6. Eigenmann PA, Haenggeli CA. Food colourings and preservatives-allergy and hyperactivity. Lancet. 2004;364(9437):823-4. https://doi.org/10.1016/S0140-6736(04)16996-1

7. Kanarek RB. Artificial food dyes and attention deficit hyperactivity disorder. Nutr Rev. 2011;69(7):385-91. https://doi.org/10.1111/ j.1753-4887.2011.00385.x

8. Wilson BG and Bahna SL. Adverse reactions to food additives. Ann Allergy Asthma Immunol. 2005;95(6):499-507. https:// doi.org/10.1016/S1081-1206(10)61010-1

9. Gultekin F, Doguc DK. Allergic and immunologic reactions to food additives. Clin Rev Allergy Immunol. 2013;45(1):6-29. https://doi.org/10.1007/s12016-012-8300-8

10. Cuce G, Cetinkaya S, Isitez N, Kuccukturk S, Sozen ME, Kalkan $S$, et al. Effects of curcumin on methyl methanesulfonate damage to mouse kidney. Biotech Histochem. 2016;91(2):122-7. https://doi.org/10.3109/10520295.2015.1099737

11. Seflek HN, Kalkan S, Cuce G, Kilınc I, Sozen ME. Effects of Nigella sativa oil on ovarian volume, oxidant systems, XIAP and NF-kB expression in an experimental model of diabetes. Biotech Histochem. 2019;94(5):325-33. https://doi.org/10.1 080/10520295.2019.1566571

12. Reyes FG, Valim MF, Vercesi AE. Effect of organic synthetic food colours on mitochondrial respiration. Food Addit Contam. 1996;13(1):5-11. https://doi.org/10.1080/02652039609374376
13. D'Amico F, Skarmoutsou E, Mangano K, Malaponte G, Mazzarino MC. Isoproterenol modulates matrix metalloproteinase-2 (MMP-2) and its tissue inhibitor-2 (TIMP-2) in rat parotid gland. Arch Oral Biol. 2013;58(4):370-6. https://doi.org/10.1016/j. archoralbio.2012.08.009

14. Takahashi S, Uekita H, Kato T, Yuge F, Ushijima N, Inoue K, et al. Immunohistochemical and ultrastructural investigation of acinar cells in submandibular and sublingual glands of rats fed a liquid diet. Tissue Cell. 2014;46(2):136-43. https://doi. org/10.1016/j.tice.2014.01.001

15. Zhang J, Cui L, Xu M, Zheng Y. Restoring the secretory function of irradiation-damaged salivary gland by administrating deferoxamine in mice. PLoS ONE. 2014;9(11):e113721. https:// doi.org/10.1371/journal.pone.0113721

16. Boz C, Ozmenoglu M, Velioglu S, et al. Matrix metalloproteinase-9 (MMP-9) and tissue inhibitor of matrix metalloproteinase (TIMP-1) in patients with relapsing-remitting multiple sclerosis treated with interferon beta. Clin Neurol Neurosurg. 2006;108(2):124-8. https://doi.org/10.1016/j.clineuro.2005.01.005

17. Lee SE, Lew W. The increased expression of matrix metalloproteinase-9 messenger RNA in the non-lesional skin of patients with large plaque psoriasis vulgaris. Ann Dermatol. 2009;21(1):27-34. https://doi.org/10.5021/ad.2009.21.1.27

18. Arthur MJ. Collagenases and liver fibrosis. J Hepatol. 1995;22(Suppl 2):43-8. PMID: 7665849

19. Groten JP, Butler W, Feron VJ, et al. An analysis of the possibility for health implications of joint actions and interactions between food additives. Regul Toxicol Pharmacol. 2000;31(1):77-91. https://doi.org/10.1006/rtph.1999.1356

20. Park M, Park HR, Kim SJ, Kim MS, Kong KH, Kim HS, et al. Risk assessment for the combinational effects of food color additives: neural progenitor cells and hippocampal neurogenesis. J Toxicol Environ Health A. 2009;72(21-22):1412-23. https:// doi.org/10.1080/15287390903212816

21. Lau K, McLean WG, Williams DP, Howard CV. Synergistic interactions between commonly used food additives in a developmental neurotoxicity test. Toxicol Sci. 2006;90(1):17887. https://doi.org/10.1093/toxsci/kfj073

22. Ashida H, Hashimoto T, Tsuji S, Kanazawa K, Danno G. Synergistic effects of food colors on the toxicity of 3-amino-1,4dimethyl-5H-pyrido[4,3-b]indole (Trp-P-1) in primary cultured rat hepatocytes. J Nutr Sci Vitaminol (Tokyo). 2000;46(3):130-6. https://doi.org/10.3177/jnsv.46.130 